\title{
O campo de estudos de usuários na ciência da informação brasileira: uma revisão sistemática da literatura
}

\author{
Virginia Lucia Rodrigues \\ Mestranda; Universidade FUMEC, Belo Horizonte, MG, Brasil; \\ virgynia.rodrigues@gmail.com \\ Ana Maria Pereira Cardoso \\ Doutora; Universidade FUMEC, Belo Horizonte, MG, Brasil; \\ ana.cardoso@fumec.br
}

\begin{abstract}
Resumo: Pesquisas no campo de estudo de usuários são instrumentos que podem ajudar bibliotecas e unidades de informação a conhecer as necessidades informacionais do público a que atendem. Este artigo relata revisão sistemática da literatura realizada com o objetivo de identificar artigos originados de pesquisas sobre comportamento informacional, de forma a verificar o estágio atual das pesquisas brasileiras nesse campo. A revisão teve como fonte a Base de Dados Referenciais de Artigos de Periódicos em Ciência da Informação (BRAPCI) cobrindo o período de 2012-2016. Os resultados evidenciaram a consolidação da área de estudos de usuários, sendo ressaltada predominância da biblioteca universitária como objeto dos artigos analisados. Constatou-se ainda que estudos de usuários são considerados mecanismos de avaliação e instrumentos para se conhecer a comunidade atendida. $O$ artigo traz contribuições para a reflexão dos pesquisadores e a identificação de novos problemas de pesquisa.
\end{abstract}

Palavras-chave: Estudos de usuários. Estudos de uso. Comportamento informacional. Revisão sistemática de literatura.

\section{Introdução}

O campo de estudo de usuário da informação também denominado estudo de comportamento informacional (ARAUJO, 2010) é o tema desse trabalho. O objetivo do artigo foi verificar o estágio atual das pesquisas brasileiras sobre esse tema, identificando: 1) quais métodos e técnicas para coleta de dados empíricos têm sido mais utilizados; 2) quais os tipos/ grupos de usuários mais estudados, a partir de sua caracterização, profissão e ambiente. 
Reconhecendo a importância desse conhecimento para desenvolvimento da teoria e das práticas da Ciência da Informação, vários autores se dedicaram, em anos recentes, a consolidar por meio de trabalhos de revisão, o estado da arte dos Estudos de Usuários (EU) na literatura brasileira, abordando aspectos teóricos e metodológicos. Podem ser citados:

a) Araújo (2009) mapeou artigos sobre 'estudos de usuário da informação' publicados em sete periódicos brasileiros entre 1998 e 2007;

b) Hyodo (2009) analisou a temática 'necessidade de informação', na revista Ciência da Informação, cobrindo o período de 1997 a 2007;

c) Nascimento (2010) analisou a estrutura dos planos de ensino da disciplina de 'Usuário da Informação', ministrada entre 2007 e 2009, nos cursos de Biblioteconomia de universidades brasileiras;

d) Nascimento (2011) descreveu a origem, histórico e desenvolvimento dos 'estudos de usuário', desde a década de 1970, e a disciplina no currículo dos cursos de Biblioteconomia;

e) Ramalho (2012) pesquisou os estudos sobre 'necessidade de informação', na revista Informação e Sociedade: Estudos, no período de 2002 a 2011;

f) Cunha, Amaral e Dantas (2015) elaboraram manual de estudos de usuários da informação destinado aos profissionais e estudantes de Biblioteconomia e Ciência da Informação. O trabalho, além de abordar aspectos históricos de estudos de usuários publicados em língua inglesa e em língua espanhola, enfatiza a produção brasileira na área apresentando os principais fundamentos teóricos e modelos propostos por diferentes autores, bem como regras e fórmulas para obter resultados de valor em sua aplicação prática.

Pretendeu-se com a pesquisa aqui relatada complementar as informações disponíveis, por meio de artigos publicados nas revistas da área, cobrindo o período 2012-2016, portanto dando continuidade aos trabalhos anteriormente publicados. Para tanto, utilizou-se do método de revisão sistemática da literatura (RSL), procedimento de pesquisa científica que visa identificar, avaliar e interpretar trabalhos publicados sobre um determinado tópico de interesse, 
durante um período de tempo delimitado seguindo um protocolo definido por antecipação.

O artigo começa com a caracterização do campo de Estudos de Usuários na Ciência da Informação, expondo sua importância e desenvolvimento. A seção seguinte apresenta os procedimentos metodológicos que guiaram a pesquisa foco do artigo, para, em seguida, apresentar os resultados encontrados e as reflexões decorrentes.

\section{Estudos de usuários de informações}

A Ciência da Informação busca, desde seus primórdios, conhecer o perfil dos usuários, por meio da realização de estudos que ajudaram a sedimentar a prática de pesquisa na área. Estudos de usuários, segundo Araújo (2010, p. 24), detém relevância “[...] significativa no campo de Biblioteconomia e Ciência da Informação, constituindo, algumas vezes, a temática mais estudada [...] em alguns programas de pós-graduação brasileiros.”.

Em texto datado de 1994, Figueiredo já indicava a caracterização e abrangência do campo de EU afirmando que os estudos de usuários são

[...] investigações que se fazem para saber o que os indivíduos precisam em matéria de informação, ou então, para saber se as necessidades de informação por parte dos usuários de uma biblioteca ou um centro de informação estão sendo satisfeitas de maneira adequada. (FIGUEIREDO, 1994, p. 7).

O aparecimento dos estudos de usuários pode ser compreendido a partir de dois movimentos: primeiro, os estudos de 1930 da Escola de Chicago desenvolvidos para a integração de grupos imigrantes na comunidade americana através da biblioteca pública. Eram estudos que tinham como meta compreender o uso da biblioteca em si, recorriam a questionários e entrevistas buscando saber o que as pessoas liam, como faziam uso da biblioteca, com que frequência as usavam, pois como lembra Figueiredo (1994, p. 21) “[...] era função das bibliotecas públicas elevar, educar e recrear as pessoas [...]”, sendo, portanto, os usuários os melhores informantes. 
Deve ser notado que este tipo de estudo refletia o ambiente científico da Universidade de Chicago, que nesta mesma época, destacava-se pelo desenvolvimento de estudos sociológicos empíricos para os quais "[...] os pesquisadores [...] inventavam, criavam métodos, coletando autobiografias, analisando cartas e outros documentos, e fazendo entrevistas." (GODOY, 1995, p. 59).

O segundo momento é o da Conferência sobre Informação Científica, realizada em 1948, pela Royal Society, em Londres. Na ocasião foram apresentados estudos que buscavam entender as necessidades dos usuários de informação científica. Nesta fase buscava-se saber como os cientistas e técnicos procediam para obter informação, ou como usavam a literatura. Figueiredo (1994, p. 27) descreve que “[...] esses estudos são canais de comunicação que se abrem entre a biblioteca e a comunidade a qual ela serve [...]”, assim, os usuários deixavam de ser meros informantes sobre o uso das coleções das bibliotecas e passavam a ser o centro dos serviços oferecidos pelas bibliotecas, ao serem encorajados a falar sobre suas necessidades de informação.

Impulsionadas por esses dois marcos, as primeiras investigações no campo dos estudos de usuários se disseminam e favorecem a ampliação no número de pesquisas (GASQUE; COSTA, 2010). Com o crescimento da literatura especializada internacional, descrevendo estudos de usuários, tornouse necessário implantar serviços voltados para a seleção dos mais relevantes nasceram, assim, as chamadas revisões críticas da literatura em assuntos especializados (PINHEIRO, 1982).

Em 1966, o campo de EU teve sua primeira revisão crítica publicada pela Annual Review of Information Science and Technology (ARIST), conceituada publicação da área. O capítulo Information Needs and Uses in Science and Technology, de autoria de H. Menzel (1966), abordou estudos sobre necessidades e usos de informação nas áreas de ciência e tecnologia, inaugurando a série de revisões que se seguiu nos anos posteriores. $\mathrm{O}$ autor realizou análises quantitativas de 1963 a 1965 para estabelecer definições e conceitos sobre o tema ${ }^{1}$ (BAPTISTA; CUNHA, 2007; GASQUE; COSTA, 2010; RABELLO 2013). 
Em 1968, na terceira revisão publicada pela ARIST, William Paisley (1968) destacou que problemas metodológicos tornavam os estudos inconclusivos, o que demonstrava que o campo ainda estaria em processo de amadurecimento. Ressaltou que os trabalhos deixavam de considerar aspectos significativos, tais como a grande quantidade de fontes de informação disponíveis; o contexto em que as informações eram usadas; a motivação e outros fatores que afetam os usuários e o trabalho por eles desenvolvido, sugerindo que o fortalecimento do campo demandava melhores definições metodológicas (GASQUE; COSTA, 2010).

Em 1986, Dervin e Nilan realizaram um trabalho, que se tornou um clássico da área (ARAUJO, 2009, p. 24), pois ao analisar os trabalhos publicados vislumbraram o aparecimento de um modo novo de abordagem, em oposição à abordagem tradicional, o paradigma que denominaram de alternativo. Segundo a abordagem alternativa, os EU devem levar em consideração os aspectos cognitivos e psicológicos buscando conhecer as necessidades individuais dos usuários, denotando a influência do emergente paradigma do cognitivismo, em contraposição ao paradigma behaviorista até então predominante.

A literatura aponta como modelos da abordagem alternativa: Taylor (1982), Belkin, Oddy, Brooks (1982), Dervin (1983), Kuhlthau (1991), Ellis (1989), Ellis, Cox, Hall (1993), Wilson (1981, 1999), Wilson e Daves (1997) e Choo (2003). Esses autores desenvolveram modelos que buscavam entender como se dá o processo de busca e uso da informação por parte dos usuários, ampliando, com a inserção de outros grupos e comunidades, o foco dos estudos da abordagem tradicional, até então centrados em cientistas e engenheiros (COSTA; SILVA; RAMALHO, 2009).

Seguindo tal perspectiva, que vê o usuário como sujeito ativo, ganharam destaque os estudos sobre o comportamento informacional empregando procedimentos e técnicas qualitativos e se apropriando de conceitos de outros campos de pesquisa, como as ciências comportamentais.

Críticas aos modelos tradicionais de estudos de uso e aos alternativos, de comportamento informacional, deram lugar a uma concepção do usuário como 
produtor de conhecimentos, inserido em práticas sociais contextualizadas. Conforme destacado por Talja (1997) e citado por Araújo:

[...] essa nova abordagem não seria nem system-centered (como são os estudos de uso da informação), nem user-centered (como são os estudos em comportamento informacional, mas sim knowledge formation-centered, isto é, sensível à percepção de como o usuário assume distintas condições de sujeito conforme o contexto e também conforme a sua inserção social. (TALJA, 1997 apud ARAUJO, 2016, p. 65).

No Brasil, a atenção aos usuários e suas necessidades foi introduzida no campo da Biblioteconomia, sobretudo por influência de docentes que traziam de seus estudos nos Estados Unidos e Inglaterra (décadas de 1970 e 1980) o interesse por este conhecimento e pela realização de pesquisas, promovendo assim a introdução de métodos e técnicas de pesquisa como disciplina nos cursos de graduação.

Kremer (1980, p. 12) realizou revisão de literatura concluindo que, algumas vezes, estudos anteriores não utilizavam técnicas consistentes constatando que em "[...] trinta anos de estudos de usuários, muitos estudos simplesmente coletaram dados sem lhes extrair uma conclusão significativa por carecerem de uma metodologia de pesquisa cuidadosa e bem selecionada [...]", justificando, assim, o ensino de metodologia científica aos futuros profissionais bibliotecários.

Como se verifica pela literatura, no caminho percorrido pelos EU, inicialmente $\mathrm{o}$ foco de pesquisa foram os cientistas e engenheiros (FIGUEIREDO, 1994). Para Dias e Pires (2004), os usuários estudados apareciam agrupados em categorias sócio-profissionais, como especialidades e/ou natureza da atividade para qual a informação é procurada.

Uma vertente do campo de EU, chamados estudos de comunidades, voltou-se para os usuários de bibliotecas, sobretudo as públicas, quando grupos numerosos foram alvo de estudos exploratórios que empregavam questionários e entrevistas para obtenção de dados quantitativos sobre a demanda e o fluxo da informação. 
Sobre o foco dos estudos de usuários, Case (2006) identificou na literatura três categorias de estudo de usuários que levam em conta:

a) profissão (gerentes, cientistas);

b) papel desempenhado na vida (alunos, pacientes); e

c) aspectos demográficos (idade, gênero, grupos étnicos).

As técnicas mais indicadas para coleta de dados em estudos de usuários, de acordo com Figueiredo (1994), eram o questionário, a entrevista, o diário, a observação direta, o controle da interação do usuário com o sistema computadorizado, a análise de tarefas, o uso de dados quantitativos e a técnica do incidente critico.

Em trabalho mais recente, Dias e Pires (2004) destacaram como motivação para conduzir estudos de usuários o entendimento de que o usuário é:

a) a principal razão da existência dos sistemas de informação;

b) a verificação da satisfação dos usuários no uso do sistema de informação;

c) a verificação da satisfação das necessidades informacionais por parte do serviço prestado.

No mesmo artigo apresentaram como técnicas aplicadas: a observação, a entrevista, o questionário, o diário, o survey - descrito como a obtenção de dados ou informações sobre características, ações ou opiniões de determinado grupo de pessoas representante de uma população alvo por meio de um instrumento de pesquisa, geralmente um questionário (DIAS; PIRES, 2004).

\section{Procedimentos metodológicos}

O presente artigo apresenta os resultados de um estudo conduzido segundo o método científico de revisão sistemática da literatura para localizar e identificar relatos de pesquisa sobre usuários da informação publicados na literatura brasileira da área de Ciência da Informação entre os anos de 2012 e 2016 . O recorte temporal decorreu do interesse em dar continuidade a trabalhos anteriores que mapearam a presença do tema na literatura científica brasileira publicada até 2011, conforme descrito na introdução. 
O método de revisão sistemática da literatura permite a execução de trabalhos que, segundo Sampaio e Mancini (2007), desempenham duas importantes funções na ciência:

a) Histórica: por apresentarem a evolução do campo científico, constituindo-se em parte integral do desenvolvimento da ciência;

b) Atualização: por fornecerem aos profissionais de qualquer área, informação sobre o estágio corrente da ciência e sua literatura, possibilitando ao pesquisador aumentar seu conhecimento sobre assuntos que já foram estudados por outros pesquisadores e os resultados alcançados.

A revisão sistemática da literatura sobre Estudo de Usuários foi realizada na Base de Dados Referenciais de Artigos de Periódicos em Ciência da Informação (BRAPCI), com os descritores: "Estudo de usuários", "Usuários da informação", "Necessidades de informação", "Ciência da Informação", gerando como expressão de busca estudo de usuários AND usuários da informação AND necessidade de informação AND Ciência da Informação realizada na opção Palavra-chave. A consulta à BRAPCI foi efetuada durante o período de dezembro de 2015 a junho de 2016.

Artigos e comunicações apresentados nos eventos Encontro Nacional de Pesquisa e Pós-Graduação em Ciência da Informação (ENANCIB) e Seminário Nacional de Bibliotecas Universitárias (SNBU) dos anos estudados trataram do tema de estudo de usuários relacionados às competências informacionais requeridas para o acesso à informação por meio de tecnologias digitais. Embora estes enfoques estejam inseridos no campo em uma abordagem mais ampla como estudos de usuários, não atendiam ao critério de inclusão definido a priori no protocolo da revisão sistemática da literatura.

Foi definido como critério de inclusão para a análise tratar-se de estudo empírico que atendesse à caracterização atribuída por Figueiredo (1994, p. 7) antes mencionada, a saber: o artigo deveria relatar pesquisa sobre o que os usuários precisam ou sobre o atendimento às suas necessidades por parte de bibliotecas ou centros de informação. 


\section{Resultados}

Trinta e quatro artigos foram recuperados. Vinte e cinco desses foram descartados por se tratarem de artigos de revisão ou conceituais ou de pesquisas em andamento, não atendendo, portanto, ao critério de inclusão. Os nove artigos restantes foram analisados por terem se caracterizado como estudos empíricos de usuários da informação, como mostra o Quadro 1.

Quadro 1 - Artigos analisados

\begin{tabular}{|c|c|c|c|c|}
\hline No. & Autor (es) & Título & Periódico & $\begin{array}{l}\text { Ano de } \\
\text { publica } \\
\text { ção }\end{array}$ \\
\hline 1 & $\begin{array}{l}\text { CARIBÉ, Rita de Cássia do } \\
\text { Vale; OLIVEIRA, Evelaine } \\
\text { Santos de }\end{array}$ & $\begin{array}{l}\text { Avaliação do tesauro do Tribunal } \\
\text { de Contas do Distrito Federal a } \\
\text { partir dos usuários }\end{array}$ & $\begin{array}{l}\text { Revista Digital de } \\
\text { Biblioteconomia \& Ciência } \\
\text { da Informação, v.13,n.1. } \\
\text { (Qualis B1) }\end{array}$ & 2015 \\
\hline 2 & $\begin{array}{l}\text { FIGUEIREDO, Dijanice Alves; } \\
\text { PAIVA, Eliane Bezerra }\end{array}$ & $\begin{array}{l}\text { Estudo do Comportamento } \\
\text { Informacional dos usuários da } \\
\text { Médiathèque Simone de } \\
\text { Beauvoir da Aliança Francesa } \\
\text { João Pessoa }\end{array}$ & $\begin{array}{l}\text { Encontros Bibli: Revista } \\
\text { Eletrônica de } \\
\text { Biblioteconomia e Ciência } \\
\text { da Informação, v.20, n.42. } \\
\text { (Qualis B1) }\end{array}$ & 2015 \\
\hline 3 & $\begin{array}{l}\text { CAETANO, Ana Carolina de } \\
\text { Souza; FERNANDES, Geni } \\
\text { Chaves }\end{array}$ & $\begin{array}{l}\text { Qual biblioteca universitária? } \\
\text { Ações das bibliotecas } \\
\text { universitárias mineiras e as } \\
\text { necessidades informacionais de } \\
\text { seus pesquisadores }\end{array}$ & $\begin{array}{l}\text { Em Questão: Revista da } \\
\text { Faculdade de } \\
\text { Biblioteconomia e } \\
\text { Comunicação da UFRGS, } \\
\text { v.21,n.1. Qualis B1) }\end{array}$ & 2015 \\
\hline 4 & $\begin{array}{l}\text { SOARES, Luciana Matias } \\
\text { Felício; SOUSA, Caissa Veloso }\end{array}$ & $\begin{array}{l}\text { Percepção da qualidade de } \\
\text { serviços nas bibliotecas da } \\
\text { Universidade Federal de Ouro } \\
\text { Preto na perspectiva do usuário }\end{array}$ & $\begin{array}{l}\text { Perspectivas em Ciência da } \\
\text { Informação, v.20,n.2. } \\
\text { (Qualis A) }\end{array}$ & 2015 \\
\hline 5 & $\begin{array}{l}\text { COSTA, Maria Elizabeth de } \\
\text { Oliveira; SANTOS, Marizete } \\
\text { Silva; BARBOSA, Anderson } \\
\text { Luiz da Rocha }\end{array}$ & $\begin{array}{l}\text { Educação a distância e as } \\
\text { bibliotecas universitárias: uma } \\
\text { interação necessária }\end{array}$ & $\begin{array}{l}\text { Perspectivas em Ciência da } \\
\text { Informação, v.20, n.2. } \\
\text { (Qualis A) }\end{array}$ & 2015 \\
\hline 6 & $\begin{array}{l}\text { CAMPOS, Cirlei Oraci Dias de; } \\
\text { SILVA, Emanoel Quartiero; } \\
\text { PINTO, Marli Dias de Souza }\end{array}$ & $\begin{array}{l}\text { A satisfação de usuários da } \\
\text { informação jurídica: estudo na } \\
\text { biblioteca da OAB/SC }\end{array}$ & $\begin{array}{l}\text { Perspectivas em Ciência da } \\
\text { Informação,v.20, n.3. } \\
\text { (Qualis A) }\end{array}$ & 2015 \\
\hline 7 & $\begin{array}{l}\text { FELÍCIO, Joana Carla de Souza } \\
\text { Matta }\end{array}$ & $\begin{array}{l}\text { Serviço de Referência Educativo } \\
\text { (SRE) em bibliotecas } \\
\text { universitárias: análise das } \\
\text { práticas voltadas ao } \\
\text { desenvolvimento da competência } \\
\text { em informação de seus usuários }\end{array}$ & $\begin{array}{l}\text { Encontros Bibli: Revista } \\
\text { Eletrônica de } \\
\text { Biblioteconomia e Ciência } \\
\text { da Informação, v.20, n.43. } \\
\text { (Qualis B1) }\end{array}$ & 2015 \\
\hline 8 & $\begin{array}{l}\text { BERTI, Ilemar Christina } \\
\text { Lansoni Wey; BARTALO, } \\
\text { Linete; ARAÚJO, Carlos } \\
\text { Alberto de Ávila }\end{array}$ & $\begin{array}{l}\text { Comportamento informacional } \\
\text { de pais de crianças com } \\
\text { Síndrome de Down }\end{array}$ & $\begin{array}{l}\text { Informação \& Informação, } \\
\text { v.19, n.1. } \\
\text { (Qualis B1) }\end{array}$ & 2014 \\
\hline 9 & $\begin{array}{l}\text { FIGUEIREDO, Helton Araújo; } \\
\text { MORAIS, Laudereida Eliana } \\
\text { Marques; RAMALHO, } \\
\text { Francisca Arruda }\end{array}$ & $\begin{array}{l}\text { Busca da informação para } \\
\text { qualificação: um estudo com } \\
\text { candidatos ao mestrado em } \\
\text { Ciência da Informação do } \\
\text { programa de pós-graduação em } \\
\text { Ciência da Informação - UFPB }\end{array}$ & $\begin{array}{l}\text { Informação \& Sociedade: } \\
\text { Estudos, v.23, n.2 } \\
\text { (Qualis B1) }\end{array}$ & 2013 \\
\hline
\end{tabular}

Fonte: BRAPCI - www.brapci.ufpr.br

Como pode ser percebido pelo Quadro 1, houve uma maior concentração de artigos descrevendo pesquisas empíricas com usuários no ano de 2015. Os resultados da análise dos artigos que atenderam aos critérios estabelecidos no 
protocolo desta revisão não permitem definir a existência de uma linha editorial destinada a esta temática entre os periódicos da área, embora a revista Perspectivas em Ciência da Informação tenha publicado três dos nove artigos, e a Encontros Bibli: Revista Eletrônica de Biblioteconomia e Ciência da Informação, dois.

Como é do conhecimento dos pesquisadores de Ciência da Informação e Biblioteconomia no Brasil, o índice de classificação de periódicos divulgado pela CAPES, através do WEB-Qualis, exerce grande pressão sobre os autores na definição do periódico ao qual submete sua produção, especialmente àqueles que atuam como docentes em programas de pós-graduação. Nesse sentido, pode se constituir como interessante problema de pesquisa entender os critérios dos autores para escolha de onde publicar, notadamente pela pouca ênfase dada à edição de números temáticos em revistas de Ciência da Informação editadas no país.

Para melhor entendimento do estado da arte dos EU no Brasil, os artigos identificados pela RSL foram analisados com o detalhamento dos descritores adotados por seus autores, as categorias profissionais estudadas, os métodos e técnicas empregados e o local da pesquisa. Tal detalhamento é apresentado no Quadro 2.

Quadro 2 - Detalhamento da análise dos artigos selecionados

\begin{tabular}{|c|c|c|c|c|}
\hline No. & Descritores (palavras chave) & Categoria profissional & Métodos e técnicas & Local \\
\hline 1 & $\begin{array}{l}\text { Ciência da Informação; Avaliação de } \\
\text { tesauro; Usuário da informação; } \\
\text { Tribunal de Contas do Distrito } \\
\text { Federal. }\end{array}$ & $\begin{array}{l}\text { Usuários do sistema } \\
\text { de processo eletrônico } \\
\text { (e-TCDF) }\end{array}$ & $\begin{array}{l}\text { Pesquisa exploratória, } \\
\text { qualitativa com uso de } \\
\text { entrevista }\end{array}$ & $\begin{array}{l}\text { Tribunal de } \\
\text { Contas do DF }\end{array}$ \\
\hline 2 & $\begin{array}{l}\text { Ciência da Informação; } \\
\text { Biblioteconomia; Comportamento } \\
\text { informacional; Estudo de usuários; } \\
\text { Busca e uso da informação. }\end{array}$ & Estudantes & $\begin{array}{l}\text { Pesquisa descritiva, } \\
\text { quantitativa, uso de } \\
\text { questionário }\end{array}$ & $\begin{array}{l}\text { Médiathéque } \\
\text { Simone de } \\
\text { Beauvoir da } \\
\text { Aliança } \\
\text { Francesa }\end{array}$ \\
\hline 3 & $\begin{array}{l}\text { Ciência da Informação; } \\
\text { Biblioteconomia; Bibliotecas } \\
\text { universitárias; Biblioteconomia para } \\
\text { pesquisa; Pós-graduação e pesquisa. }\end{array}$ & $\begin{array}{l}\text { Estudantes, } \\
\text { professores } \\
\text { e bibliotecários }\end{array}$ & $\begin{array}{l}\text { Pesquisa descritiva, } \\
\text { quantitativa, com uso } \\
\text { de } \\
\text { questionário }\end{array}$ & $\begin{array}{l}\text { Bibliotecas } \\
\text { universitárias }\end{array}$ \\
\hline 4 & $\begin{array}{l}\text { Ciência da Informação, } \\
\text { Administração; Qualidade de } \\
\text { serviços; Servqual; Libqual; } \\
\text { Bibliotecas universitárias. }\end{array}$ & Estudantes & $\begin{array}{l}\text { Pesquisa descritiva, } \\
\text { Quantitativa, Estudo de } \\
\text { caso com o uso de } \\
\text { questionário }\end{array}$ & $\begin{array}{l}\text { Bibliotecas } \\
\text { universitárias - } \\
\text { Univ. Fed. Ouro } \\
\text { Preto }\end{array}$ \\
\hline 5 & $\begin{array}{l}\text { Educação a distância (EAD); } \\
\text { Bibliotecas Universitárias; Polos de } \\
\text { Apoio Presencial; Universidade } \\
\text { Federal de Minas Gerais (UFMG). }\end{array}$ & Estudantes & $\begin{array}{l}\text { Pesquisa exploratória, } \\
\text { Quali-quantitativo, } \\
\text { com uso de } \\
\text { questionário }\end{array}$ & $\begin{array}{l}\text { Bibliotecas dos } \\
\text { polos de apoio } \\
\text { presencial da } \\
\text { EAD - Univ. } \\
\text { Fed. Minas } \\
\text { Gerais }\end{array}$ \\
\hline
\end{tabular}




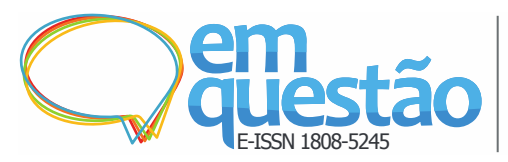

O campo de estudos de usuários na ciência d ainformação brasileira: uma revisão sistemática da literatura

Virginia Lucia Rodrigues, Ana Maria Pereira Cardoso

\begin{tabular}{|c|l|l|l|l|}
\hline 6 & $\begin{array}{l}\text { Estudo de usuários; Satisfação de } \\
\text { usuários; Usuários da informação } \\
\text { jurídica; Biblioteca jurídica. }\end{array}$ & $\begin{array}{l}\text { Usuários da } \\
\text { Biblioteca }\end{array}$ & $\begin{array}{l}\text { Pesquisa exploratória e } \\
\text { descritiva, } \\
\text { Quantitativa, Estudo de } \\
\text { caso com o uso de } \\
\text { questionário }\end{array}$ & $\begin{array}{l}\text { Biblioteca } \\
\text { jurídica - } \\
\text { OAB/SC }\end{array}$ \\
\hline 7 & $\begin{array}{l}\text { Ciência da Informação; Bibliotecas } \\
\text { universitárias; Serviço de referência } \\
\text { educativo; Educação de usuários; } \\
\text { Competência em informação. }\end{array}$ & Bibliotecários & $\begin{array}{l}\text { Pesquisa exploratória e } \\
\text { descritiva, Quali- } \\
\text { quantitativa, uso de } \\
\text { questionário }\end{array}$ & $\begin{array}{l}\text { Bibliotecas } \\
\text { universitárias } \\
\text { públicas }\end{array}$ \\
\hline 8 & $\begin{array}{l}\text { Comportamento informacional; } \\
\text { Significado cultural atribuído à } \\
\text { deficiência; Síndrome de Down. (este } \\
\text { artigo não determina as palavras } \\
\text { chave, optou-se por usar os } \\
\text { descritores adotados para a busca na } \\
\text { BRAPCI) }\end{array}$ & $\begin{array}{l}\text { Pais de crianças com } \\
\text { Síndrome de Down. }\end{array}$ & $\begin{array}{l}\text { Pesquisa exploratória, } \\
\text { uso de } \\
\text { entrevista } \\
\text { semiestruturada }\end{array}$ & $\begin{array}{l}\text { Instituto } \\
\text { Londrinense de } \\
\text { Educação para } \\
\text { Crianças } \\
\text { Excepcionais } \\
\text { (ILECE/PR) }\end{array}$ \\
\hline $\begin{array}{l}\text { Ciência da Informação; Estudo de } \\
\text { usuários; Busca de informação; } \\
\text { Necessidade de informação; } \\
\text { Programa de Pós-Graduação em } \\
\text { Ciência da Informação da UFPB }\end{array}$ & $\begin{array}{l}\text { Estudantes candidatos } \\
\text { a curso de mestrado }\end{array}$ & $\begin{array}{l}\text { Pesquisa descritiva, } \\
\text { quantitativa, uso de } \\
\text { questionário }\end{array}$ & $\begin{array}{l}\text { Univ. Fed. } \\
\text { Paraíba }\end{array}$ \\
\hline
\end{tabular}

Fonte: BRAPCI - www.brapci.ufpr.br

A análise dos descritores dos documentos teve como base os metadados disponíveis na base BRAPCI, ou seja, tratavam-se de palavras chave indicadas pelos autores dos nove artigos analisados. A presença do termo "biblioteca" em seis dos artigos pode ser confrontada à do termo "usuário(s)" usado em cinco deles. A predominância do primeiro descritor permite inferir que os EU fazem parte das preocupações de bibliotecários, interessados em entender melhor as necessidades de seu público, como forma de contraposição às crescentes ofertas de conteúdos digitais relevantes fornecidos pelas máquinas de busca em plataformas virtuais como Google, Yahoo! ou em repertórios acadêmicos acessados por meio da internet.

Merece destaque também a escolha de descritores como "comportamento informacional", "busca de informação", "necessidades de informação", "satisfação de usuários", "competência em informação", que, embora estejam dispersos no conjunto analisado, parecem indicar a predominância do paradigma cognitivo (abordagem alternativa) como opção teórica no direcionamento dos estudos.

Duas categorias analisadas confluem para a percepção de que o campo de EU encontra-se disseminado principalmente nos meios universitários: categoria profissional e local da pesquisa. De fato, cinco dos nove artigos foram realizados junto a usuários de bibliotecas universitárias, estudantes e professores, ou também bibliotecários do mesmo tipo de biblioteca. Digno de 
menção é o artigo de número oito, por sua absoluta singularidade no conjunto: abordou o comportamento informacional de um grupo de pessoas com necessidades específicas relacionadas às suas vivências cotidianas. A singularidade da pesquisa advém do deslocamento face à uma instituição disseminadora de informações (biblioteca ou universidade) realçando a busca e o acesso à informação virtualizada pela internet.

Além dos aspectos listados, cabe ainda uma referência à origem geográfica das pesquisas que originaram os artigos, ainda que este não tenha sido um enfoque pré-definido pelo protocolo da RSL. Três delas foram realizadas em Minas Gerais, duas na Paraíba, e outras três localizadas cada qual em Brasília, Santa Catarina e Paraná. Um dos artigos relata o foco em bibliotecários de "bibliotecas universitárias públicas", sem mencionar a região. O que este fato parece indicar é a influência de Programas de Pós-Graduação em Ciência da Informação e/ou Biblioteconomia para destacar a importância do conhecimento sobre os processos de busca e uso de informações por parte dos usuários (ou clientes) em qualquer serviço de informação. Não por acaso, dois dos programas que possuem grupos de pesquisas que conduzem estudos sobre o tema estão localizados na Universidade Federal de Minas Gerais (UFMG) e na Universidade Federal da Paraíba (UFPB).

Finalmente, cabem comentários sobre os métodos e as técnicas adotadas pelos estudos relatados nos artigos. Também, nesse aspecto, o pequeno número de artigos analisados impede que se observe alguma tendência preponderante: quase igual número de autores definiu a natureza de suas pesquisas como descritiva (quatro), ou exploratória (três), sendo que dois as classificam como descritiva e exploratória. $\mathrm{O}$ mesmo não acontece em relação à abordagem, em que os métodos quantitativos prevalecem (seis) sobre os qualitativos (dois) ou quali-quantitativos (um). Como instrumentos de coleta de dados, o questionário detém a primazia nas escolhas, tendo sido utilizado em cinco pesquisas e a entrevista em três ocorrências.

Outras técnicas como observação, diário, survey, delphi ou incidente crítico, indicados pela literatura, não foram mencionadas. Possivelmente, esta predileção decorra da maior facilidade apresentada pelos questionários para 
elaboração (modelos disponíveis em publicações físicas e/ou digitais) e aplicação (por via digital em e-mail ou plataformas virtuais).

\section{Considerações finais}

Muito embora a RSL aqui relatada sobre pesquisas com usuários no Brasil tenha se limitado a cobrir um intervalo temporal pequeno (2012-2016), e em decorrência disto, tendo identificado um número restrito de publicações, os resultados obtidos adicionados àqueles expostos nos trabalhos que a antecederam (indicados na introdução) permitem afirmar que o campo EU está consolidado como área de estudos no Brasil.

A pouca diversidade na seleção de métodos e técnicas empregados em pesquisas com usuários parece indicar que o campo carece de maior maturidade metodológica. Como visto, o emprego de técnicas convencionais (questionários e entrevistas) é a tônica na maioria dos estudos com o propósito de identificação das necessidades de informação dos usuários.

Modelos de análise com ênfase no paradigma comportamental, como os encontrados na literatura internacional (a exemplo dos relacionados anteriormente) não aparecem nos artigos estudados e que foram publicados em periódicos brasileiros da área. Esta situação leva a crer que a constatação de Kremer (1980), mencionada na seção dois do presente artigo, continua sendo válida: faltam conclusões significativas que permitam uma elaboração teórica consistente.

Outra constatação decorrente da RSL é a relação existente entre os estudos empíricos com usuários de informação e algum tipo de serviço, fonte ou sistema de informação, de onde se infere que as pesquisas são realizadas com objetivos imediatos, de sanar deficiências ou promover melhores práticas institucionais que validem ou legitimem os serviços prestados ou as funções exercidas.

É interessante também destacar a predominância da biblioteca universitária como objeto dos estudos analisados. Tal predomínio sugere, no mínimo, duas interpretações não excludentes: o acesso a cursos de capacitação / 
qualificação aberta aos profissionais, como requisito à progressão na carreira, amplia o leque de preocupações desses profissionais com a qualidade dos serviços e a satisfação de seu público-alvo. Simultaneamente, a concorrência que as plataformas digitais fazem às bibliotecas físicas para o fornecimento de informações impõe o permanente cuidado com o atendimento eficiente das necessidades informacionais dos usuários. Ressalta-se o papel importante no ensino, aprendizagem e extensão que as bibliotecas universitárias desempenham e a positividade de serem realizados estudos para verificar as necessidades dos usuários e o nível de satisfação com os serviços prestados alcançado por eles.

A análise dos descritores empregados nos artigos revelou que os autores ampliam o foco mais tradicional do campo, "necessidades" e "satisfação", incorporando termos como "educação de usuário", "competência em informação", "qualidade de serviçoo" para referir-se aos estudos de usuários, levando a concluir que o campo encontra-se conectado com os avanços da Ciência da Informação em resposta ao desenvolvimento acelerado das tecnologias de informação e comunicação.

Finalizando, as autoras acreditam que a RSL aqui relatada cumpriu as funções científicas de registro histórico e de atualização sobre o estado da arte do campo de EU em publicações brasileiras no período estipulado como objetivo, tendo contribuído para a reflexão dos pesquisadores e a identificação de novos problemas de pesquisa.

\section{Referências}

ARAÚJO, C. A. A. Estudos de usuários conforme o paradigma social da ciência da informação: desafios teóricos e práticos de pesquisa. Informação \& Informação, Londrina, v. 15, n. 2, p. 23-39, 2010.

ARAÚJO, C. A. A. Estudos de usuários da informação: comparação entre estudos de uso, de comportamento e de práticas a partir de uma pesquisa empírica. Informação em Pauta, Fortaleza, v. 1, n.1, p. 61-78, jan./jun. 2016.

ARAÚJO, C. A. A. Um mapa dos estudos de usuários da informação no Brasil. Em Questão: Revista da Faculdade de Biblioteconomia e Comunicação da UFRGS, Porto Alegre, v. 15, n. 1, p. 11-26, 2009. 
BAPTISTA, S; CUNHA, M. B. Estudo de usuários: visão global dos métodos de coleta de dados. Perspectivas em Ciência da Informação, Belo Horizonte, v. 12, n. 2, p. 168-184, 2007.

BELKIN, N. J.; ODDY, R. N.; BROOKS, N. H. Anomalous states of knowledge in information retrieval. The Canadian Journal of Information Science, Toronto, v. 5, p. 133-143, 1982.

CASE, D. O. Information behavior. Annual Review of Information Science and Technology, New Jersey, v. 40, p. 293-327, 2006.

CHOO, Chun Wei. Como ficamos sabendo: um modelo de uso da informação. In:__. A organização do conhecimento: como as organizações usam a informação para criar significado, construir conhecimento e tomar decisões. São Paulo: SENAC, 2003. p. 63-120.

COSTA, L. F. da; SILVA, A. C. P. da; RAMALHO, F. A. (Re)visitando os estudos de usuário: entre a tradição e o alternativo. DataGramaZero: Revista de Ciência da Informação, Rio de Janeiro, v. 10, n. 4, 2009.

CUNHA, M. B.; AMARAL, S. A.; DANTAS, E. B. Manual de estudo de usuários da informação. São Paulo: Atlas, 2015..

DERVIN, B. An overview of sense-making research: concepts, methods and results to date. In: ANNUAL MEETING OF THE INTERNATIONAL COMMUNICATION ASSOCIATION, 1983. Anais... Dallas: International Communication Association, 1983.

DIAS, M. M. K.; PIRES, D. Usos e usuários da informação. São Carlos: EdUFSCar, 2004. (Série Apontamentos).

ELLIS, D. A behavioural approach to information retrieval design. Journal of Documentation, London, v. 45, n. 3, p. 171-212, 1989.

ELLIS, D.; COX, D.; HALL, K. A comparison of the information seeking of researchers in the physical and social science. Journal of Documentation, London, v. 49, n. 4, p. 356-369, 1993.

FIGUEIREDO, N. Estudos de uso e usuários da informação. Brasília, DF: IBICT, 1994.

GASQUE, K. C. G. D.; COSTA, S. Evolução teórico-metodológica dos estudos de comportamento informacional de usuários. Ciência da Informação, Brasília, DF, v. 39, n. 1, p. 21-32, 2010.

GODOY, A. S. Introdução à pesquisa qualitativa e suas possibilidades. RAE: Revista de Administração de Empresas, São Paulo, v. 35, n. 2, p. 57-63, 1995. 
HYODO, T. A literatura sobre necessidades de informação: uma análise a partir de artigos publicados no Brasil. Encontros Bibli: Revista Eletrônica de Biblioteconomia e Ciência da Informação, Florianópolis, v. 14, n. 27, p. 135145, 2009. Disponível em: <http://www.brapci.ufpr.br/brapci/v/6733> Acesso em: 16 maio 2016.

KUHLTHAU, C. Inside the search process: information seeking from the users perspective. Journal of the American Society for Information Science, New York, v. 42, n. 5, p. 361-371, 1991.

KREMER, J. M. Fluxo de informação entre engenheiros: uma revisão da literatura. Revista da Escola de Biblioteconomia da UFMG, Belo Horizonte, v. 9, n. 1, p. 7-41, 1980. Disponível em:

<http://www.brapci.ufpr.br/brapci/v/10029>. Acesso em: $21 \mathrm{dez} .2015$.

MENZEL, H. Information needs and uses in science and technology. Annual Review of Information Science and Technology, New Jersey, v. 1, p. 41-68, 1966.

NASCIMENTO, M. J. Planos de ensino de "usuário da informação" nos cursos de biblioteconomia no Brasil. DataGramaZero: Revista de Ciência da Informação, Rio de Janeiro, v. 11, n. 1, 2010. Disponível em <http://www.brapci.ufpr.br/brapci/v/8344>. Acesso em: 18 maio 2016.

NASCIMENTO, M. J. Usuário da informação como produção científica e disciplina curricular: origem dos estudos e o ensino no Brasil. Revista Digital de Biblioteconomia \& Ciência da Informação, Campinas, v. 8, n. 2, p. 41-71, 2011. Disponível em: <http://www.brapci.ufpr.br/brapci/v/9783>. Acesso em: 18 maio 2016.

PAISLEY, W. Information needs and uses. Annual Review of Information Science and Technology, New Jersey, v. 3, p. 1-30, 1968.

PINHEIRO, L. V. R. Usuário - informação: o contexto da ciência e da tecnologia. Rio de Janeiro: LTC/IBICT, 1982.

RABELLO, R. Leituras sobre usuário e uso da informação na ciência da informação. Perspectivas em Ciência da Informação, Belo Horizonte, v. 18, n. 4, p. 152-184, 2013.

RAMALHO, F. A. Produção sobre necessidade de informação: estudos no período 2002 a 2011. Informação \& Sociedade: Estudos, João Pessoa, v. 22, n. esp., 2012. Disponível em: <http://www.ies.ufpb.br> Acesso em: 18 maio 2016.

ROLIM, E. A; CENDÓN, B. V. Modelos e técnicas de estudos de usuários na ciência da informação. DataGramaZero: Revista de Ciência da Informação, Rio de Janeiro, v. 14, n. 2, 2013. 
SAMPAIO, R. F; MANCINI, M. C. Estudos de revisão sistemática: um guia para síntese criteriosa da evidência científica. Revista Brasileira de

Fisioterapia, São Carlos, v. 11, n. 1, p. 83-89, 2007.

TAYLOR, R. Value-added processes in information systems. Norwood: Ablex, 1982.

WILSON, T. D. Models in information behaviour research. Journal of Documentation, London, v. 55, n. 3, p. 249-270, 1999.

WILSON, T. D. On user studies and information needs. Journal of Documentation, London, v. 37, n. 1, p. 3-15, 1981.

WILSON, T. D.; DAVIS, K. The Centre for Research on Users Studies: aims and functions. Aslib Proceedings, London, v. 29, n. 2, p. 65-69, 1997.

\title{
The field of users' studies in Brazilian Information Science: a systematic literature review
}

\begin{abstract}
Researches in the field of users' studies are important tools to help libraries and information units to know the information needs of the public they provide. This article reports a systematic literature review conducted with the aim of identifying articles arised from research on informational behavior, in order to check the state of the art of Brazilian research in this field. The review covered the 2012-2016 period, using as source the Brazilian Information Science referencial database of periodical articles (BRAPCI). The results showed the consolidation of the field of users' studies and highlighted the university libraries as the main objects for the researchers. It was noted that users' studies are considered evaluation instruments to know the needs of the targeted people and the quality of the services provided. The article brings some contributions to the Brazilian Information Science researchers on how to find new research problems.
\end{abstract}

Keywords: Users' studies. Information use. Informational behavior. Literature review on users' studies.

Recebido em: 22/08/2016

Aceito em: 06/01/2017 
${ }^{1}$ Cunha, Amaral e Dantas (2015) atualizaram e ampliaram trabalho de Rolim e Cendón (2013), que analisaram os capítulos sobre Estudos de Usuários publicados pelo ARIST até 1990. A atualização foi feita até o ano de 2011 e apresentou também a indicação do numero de artigos publicados em cada capítulo bem como a evolução dos temas tratados pelo.

2 TALJA, S. Constituting "information" and "user" as research objects: a theory of knowledge formations as an alternative to the information-man theory. In: VAKKARI, P.; SAVOLAINEN, R.; DERVIN, B. (Org.). Information seeking in context. Londres: Taylor Graham, 1997. p. 67-80. Apud Araújo (2016). 